\title{
DIFFERENTIATION OF RAT SEMINIFEROUS EPITHELIUM IN ORGAN CULTURE
}

\author{
A. STEINBERGER AND E. STEINBERGER \\ Division of Endocrinology and Reproduction, Albert Einstein Medical Center, \\ Philadelphia 41, Pennsylvania, U.S.A.
}

(Received 24th September 1964)

\begin{abstract}
Summary. In-vitro differentiation of germinal epithelium from testes of adult and 12-day rats was studied with the aid of radioautography. Following a single injection of tritiated thymidine, the animals were killed and the testes grown as organ cultures. Tissue samples fixed prior to cultivation and after various time intervals of in-vitro growth, were processed for radioautography. Localization of the label in relation to the germ cell types was determined. In tissues obtained from animals $3 \mathrm{hr}$ after isotope injection, the most advanced labelled germinal cells were spermatogonia and resting primary spermatocytes. Following 3 to 7 days of cultivation, the label was present in the zygotene and leptotene stages of the meiotic prophase and after 2 to 3 weeks of cultivation, in the pachytene stage of primary spermatocytes. No labelled spermatids were found in the cultivated tissues.

Appearance of labelled pachytene spermatocytes in cultures of testicular tissue containing only labelled spermatogonia and resting spermatocytes prior to cultivation constitutes evidence that progressive, although limited, differentiation of germinal epithelium from adult and puberal rats, can take place in vitro.
\end{abstract}

\section{INTRODUCTION}

The maintenance of testicular tissue from rats of various ages in long-term cultures has been recently described; the survival of Sertoli or 'supporting cells' and primitive type A spermatogonia for periods up to 6 months was demonstrated. In tissue of puberal or adult rats, the more mature germinal epithelium cells decreased in number gradually and eventually disappeared from the seminiferous tubules. Spermatids were found in cultivated tissues during the first few days and primary spermatocytes during the first 3 to 4 weeks (Steinberger, Steinberger \& Perloff, 1964b). A question has been raised whether spermatids, and particularly spermatocytes present in the seminiferous tubules after a period of time in culture, had formed in vitro from their precursors, or whether they simply survived from the initial inoculum. The study reported in this communication was designed in an attempt to answer the above question with the aid of radioautography. Clermont, Leblond \& Messier (1959) demonstrated how the development of germinal epithelium cells in vivo can be followed 
in radioautographs of testicular tissue obtained from animals at time intervals after administration of tritiated thymidine. Since spermatogonia and resting spermatocytes are the only germinal epithelium cells which actively incorporate tritiated thymidine, the more advanced germinal cells inherit the label from their labelled precursors, at specific time intervals. In the study reported here, cultures were initiated with testicular tissue obtained from animals at determined time intervals following a single dose of tritiated thymidine. This was done to obtain labelling of specific types of germinal cells prior to cultivation. After various periods of in-vitro growth, tissue samples were processed for radioautography and the localization of the label, in relation to the germinal cell types, was determined.

\section{MATERIALS AND METHODS}

Rats of the Long-Evans strain, bred and maintained in our laboratories, were used throughout the study. Two age groups were utilized; adults (over 60 days of age), with well-established spermatogenesis and 12-day-old animals in which spermatogenesis had not progressed beyond occasional pachytene spermatocytes.

\section{Labelling procedure}

The animals received subcutaneously a single dose of tritiated thymidine $(0 \cdot 8 \mu \mathrm{c} / 100 \mathrm{~g}$ body $\mathrm{wt})$. The specific activity of the radioisotope was $6600 \mathrm{mc} /$ mM. Either $3 \mathrm{hr}$ or 12 days after isotope injection the animals were killed and their testes removed.

\section{Culture technique}

Immediately upon removal the testes were cut into small fragments and placed in culture dishes. The culture technique was the same as that described in detail previously (Steinberger, Steinberger \& Perloff, 1964a), except for doubling of the concentration of glutamine in the culture medium. The cultures were grown for the following time intervals: 3 to 7 days, 2 to 3 weeks or 4 to 6 weeks. At the termination of each time interval six or more cultured fragments were fixed in Bouin's solution, embedded in paraffin, sectioned at $4 \mu$ and stained with Harris' haematoxylin and eosin.

\section{Radioautography technique}

Liquid photographic emulsion, NTB-2, was used to coat the slides according to the technique described by Kopriwa \& Leblond (1962). After 4 to 6 weeks of exposure, the slides were developed and examined microscopically.

\section{RESULTS}

\section{Testes from adult rats obtained $3 \mathrm{hr}$ after injection of tritiated thymidine}

Radioautograms of testicular tissue prior to cultivation revealed the label to be associated with spermatogonia and resting primary spermatocytes. More advanced types of germinal cells were not labelled (Pl. 1, Fig. 1). These findings correspond with those reported by Clermont et al. (1959). 
(a) 3 to 7 day cultures. The general appearance of the culture was comparable to that reported previously (Steinberger et al., 1964b). The architecture of the seminiferous tubules and the Sertoli cells was well maintained; the germinal cells diminished in numbers. In tubules containing spermatocytes, the zygotene and leptotene stages of the meiotic prophase were clearly labelled (Pl. 1, Fig. 2). The pachytene spermatocytes and the occasional remaining spermatids were unlabelled.

(b) 2 to 3 week cultures. At this time interval, the radioautograms revealed labelling of the pachytene spermatocytes (P1. 1, Fig. 3). The number of pachytene spermatocytes was considerably smaller than that usually found in testes of normal animals of comparable age. Nevertheless, most of the spermatocytes present were labelled.

(c) 4 to 6 week cultures. The supporting cells and occasional primitive type A spermatogonia were well maintained. Most of the germinal cells had disappeared. Pachytene spermatocytes, mostly labelled, were found occasionally.

\section{Testes from 12-day-old rats obtained $3 \mathrm{hr}$ after injection of tritiated thymidine}

Radioautograms of tissues obtained prior to cultivation showed the label to be associated with spermatogonia and resting primary spermatocytes. The more advanced primary spermatocytes were unlabelled (Pl. 1, Fig. 4).

(a) 3 to 7 day cultures. A number of resting spermatocytes still contained some label. However, the zygotene and leptotene spermatocytes were now clearly labelled (Pl. 1, Fig. 5). Occasional pachytene spermatocytes found in a small number of tubules remained unlabelled.

(b) 2 to 3 week cultures. The number of leptotene and zygotene spermatocytes has decreased. Pachytene spermatocytes were present in a larger number of tubules and most of them were labelled (Pl. 1, Fig. 6). The overall number of primary spermatocytes was considerably less, however, when compared to that found in vivo in an animal of similar age.

(c) 4 to 6 week cultures. At this time, most of the germinal elements have disappeared. The seminiferous tubules were lined by Sertoli cells and contained occasional primitive type A spermatogonia. Very occasional labelled primary spermatocytes in the pachytene stage of development were observed. No spermatids were found in any of the cultures.

\section{Testes from adult rats obtained 12 days after injection of tritiated thymidine}

The radioautogram of testicular tissue obtained 12 days after the injection of thymidine, is shown in Pl. 1, Fig. 7. The most advanced labelled germinal cells are the pachytene spermatocytes. These findings are in agreement with the report of Clermont et al. (1959). If formation of spermatids from pachytene spermatocytes took place under in-vitro conditions, it would be expected to occur within the first 2 weeks of cultivation. Therefore, cultures were set up with testicular tissue obtained 12 days after isotope injection, and daily samples for 14 days were processed for radioautography. In none of the examined tissues, however, did we find labelled spermatids. 


\section{DISCUSSION}

Attempts to initiate and/or maintain mammalian spermatogenesis in tissue culture dates back to the pioneering work of Champy (1920). He claimed that, in fragment cultures of testicular tissue from adult rabbits, formation of spermatocytes from spermatogonia took place within 9 days after those initially present had degenerated. In cultures of testicular tissue from immature rats, an increase of spermatids was reported by Gaillard \& Varossieau (1938), although the explants underwent complete necrosis after several days of cultivation. Mendelsohn (1938) observed motile spermatozoa in 48-hr cultures of testicular tissue from adult rabbits and concluded that they probably formed in vitro from spermatids. It would seem from the above reports that each of the major steps of the spermatogenic process has been shown to take place in vitro: formation of spermatocytes from spermatogonia (Champy, 1920), formation of spermatids from spermatocytes (Gaillard \& Varossieau, 1938) and formation of spermatozoa from spermatids (Mendelsohn, 1938). However, closer scrutiny of these reports reveals that they were based on short-term cultures of testicular tissue from adult animals. Recent studies of Clermont et al. (1959) defined with precision the sequence of events in the spermatogenic process and the duration of each developmental stage. Thus, approximately 20 days are required for young spermatids to develop into mature spermatozoa and approximately 18 days for resting spermatocytes to go through the meiotic process and form spermatids. It seems unlikely, therefore, that short-term cultures could provide evidence for differentiation of one type of germinal epithelium cells into another. Furthermore, conclusions of the above-mentioned authors were based solely on the fact that certain cell types were found in the cultivated tissue. However, it is impossible to ascertain whether their presence indicated de-novo formation or mere survival, since the same cell types were already present in the testicular tissue prior to cultivation.

Using culture conditions which permit long-term survival of testicular tissue, it has been demonstrated that in testes of adult rats primary spermatocytes are present for 3 to 4 weeks, and spermatids for 2 to 3 days after explantation (Steinberger et al., 1964b). In the work reported here, evidence was obtained,

\section{EXPLANATION OF PLATE 1}

Radioautographs of testicular sections. Magnification $\times 450$.

Fig. 1. Testes from an adult rat, obtained $3 \mathrm{hr}$ after injection of tritiated thymidine. Most advanced germinal cells labelled are spermatogonia and resting spermatocytes.

Fic. 2. Testes from an adult rat, obtained $3 \mathrm{hr}$ after injection of tritiated thymidine and grown in culture for 3 to 7 days. Labelling of leptotene and zygotene spermatocytes.

Fig. 3. Testes from an adult rat, obtained $3 \mathrm{hr}$ after injection of tritiated thymidine and grown in culture for 2 to 3 weeks. Labelling of pachytene spermatocytes.

FIG. 4. Testes from a 12-day rat, obtained $3 \mathrm{hr}$ after injection of tritiated thymidine. Most advanced germinal cells labelled are spermatogonia and resting spermatocytes.

FIG. 5. Testes from a 12-day rat, obtained $3 \mathrm{hr}$ after injection of tritiated thymidine, and grown in culture for 3 to 7 days. Labelling of leptotene and zygotene spermatocytes.

FIG. 6. Testes from a 12-day rat, obtained $3 \mathrm{hr}$ after injection of tritiated thymidine, and grown in culture for 2 to 3 weeks. Labelling of pachytene spermatocytes.

Frg. 7. Testes from an adult rat, obtained 12 days after injection of tritiated thymidine. Most advanced germinal cells labelled are pachytene spermatocytes. 
PLATE 1
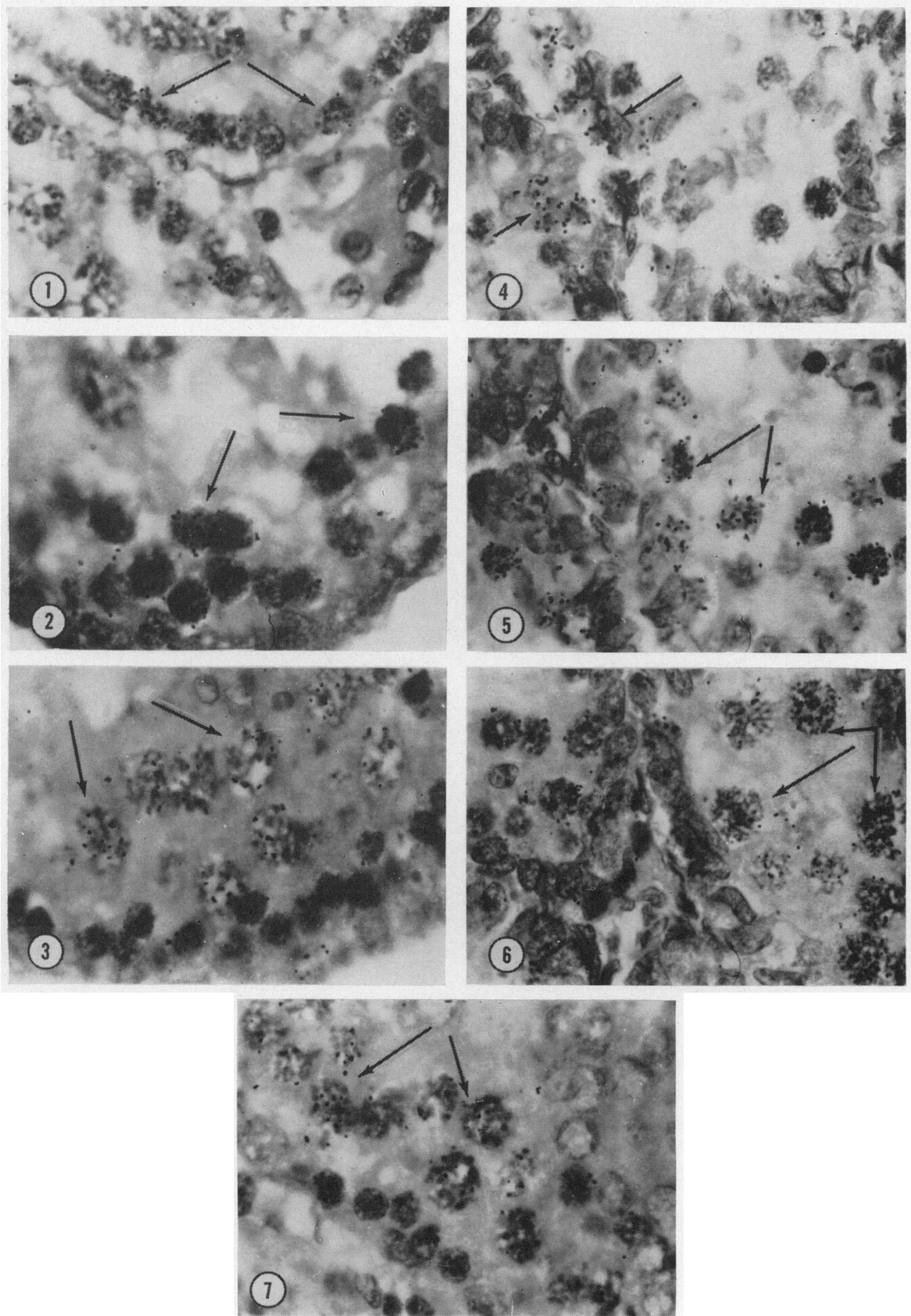

(Facing p. 246) 
with the help of radioautographic techniques which indicates that progressive differentiation of germinal epithelium cells does take place in organ culture, but to a limited extent. Thus, in cultures of testicular tissue obtained from adult or 12-day rats, $3 \mathrm{hr}$ after the administration of tritiated thymidine, the only germ cells labelled at the time of explantation were spermatogonia and resting spermatocytes. After 3 to 7 days of cultivation, the label was found to be associated with the leptotene and zygotene stages of the meiotic prophase, and, after 2 to 3 weeks of cultivation, with spermatocytes at the pachytene stage. The time intervals at which these cell types became labelled in vitro, corresponded to the time intervals found under in-vivo conditions (Clermont et al., 1959). The number of spermatocytes formed in vitro, however, was small and their formation ceased completely after 1 month. To test the possibility of spermatid formation in culture, a different experimental design was utilized. Spermatid formation would most likely be demonstrable by placing in culture tissue which contained large numbers of labelled pachytene spermatocytes, since the time necessary for these cells to become spermatids would be relatively shorter. In view of this, cultures were initiated with testes obtained from adult rats 12 days after injection of tritiated thymidine. No labelled spermatids, however, were found in radioautograms of the cultivated tissues. Apparently the employed culture conditions were adequate for formation of spermatocytes, but could not support the completion of the meiotic division and formation of spermatids. A similar situation was observed in cultures of testicular tissue from 4-day-old rats grown in the presence of vitamins A, E and C (Steinberger, Steinberger \& Perloff, 1964c), where formation of primary spermatocytes from their precursors was observed but in no instance had completion of meiotic division taken place. The appearance of labelled spermatocytes in cultures of testicular tissue was similar in adult and 12-day rats, although the tissue from younger animals showed, in general, better survival in culture. Labelling of more mature germinal cells in culture, and at a similar time sequence as that found in vivo, provides definite evidence for the progressive, although limited, differentiation of the germinal epithelium in vitro.

\section{ACKNOWLEDGMENTS}

The authors wish to thank Miss Arlene Zimring for the preparation of histologic sections and Mrs Aurora Bramante for her assistance in tissue culture and radioautography.

This investigation was supported by USPHS Grant HD 00399.

\section{REFERENGES}

Champy, Gh. (1920) De la méthode de culture des tissus. VI. Le testicule. Arch. Zool. exp. gén. 60, 461. Clermont, Y., Leblond, C. P. \& Messier, B. (1959) Durée du cycle de l'épithélium séminal du rat. Arch. Anat. micr. Morph. exp. 48, 37.

Gaillard, P. J. \& Varossieau, W. W. (1938) The structure of explants from different stages of development of the testis on cultivation in media obtained from individuals of different ages. Acta neerl. Morph. 1, 313.

Kopriwa, B. M. \& Leblond, C. P. (1962) Improvements in the coating technique of radioautography. 7. Histochem. Cytochem. 10, 269.

Mendelsohn, W. (1938) The cultivation of adult rabbit testicle in roller tubes. Anat. Rec. $69,355$. 
Steinberger, A., Steinberger, E. \& Perloff, W. H. (1964a) Mammalian spermatogenesis in vitro. Exp. Cell Res. 36, 19.

Steingerger, E., Steingerger, A. \& Perloff, W. H. (1964b) Studies on growth in organ culture of testicular tissue from rats of various ages. Anat. Rec. 148, 581.

Steingerger, E., Steingerger, A. \& Perloff, W. H. (1964c) Initiation of spermatogenesis in vitro. Endocrinology, 74, 788. 